\title{
Analysis of ACAM Data for Trace Gas Retrievals during the 2011 DISCOVER-AQ Campaign
}

\author{
C. Liu, ${ }^{1}$ X. Liu, ${ }^{1}$ M. G. Kowalewski, ${ }^{2,3}$ S. J. Janz, ${ }^{3}$ G. González Abad, ${ }^{1}$ K. E. Pickering, \\ K. Chance, ${ }^{1}$ and L. N. Lamsal ${ }^{2,3}$ \\ ${ }^{1}$ Harvard-Smithsonian Center for Astrophysics, Cambridge, MA 02138, USA \\ ${ }^{2}$ Goddard Earth Sciences Technology and Research, Universities Space Research Association, Columbia, MD 21044, USA \\ ${ }^{3}$ NASA Goddard Space and Flight Center, Greenbelt, MD 20771, USA
}

Correspondence should be addressed to C. Liu; chliu81@ustc.edu.cn

Received 15 June 2015; Accepted 30 July 2015

Academic Editor: Xiaoming Gao

Copyright (C) 2015 C. Liu et al. This is an open access article distributed under the Creative Commons Attribution License, which permits unrestricted use, distribution, and reproduction in any medium, provided the original work is properly cited.

\begin{abstract}
To improve the trace gas retrieval from Airborne Compact Atmospheric Mapper (ACAM) during the DSICOVER-AQ campaigns, we characterize the signal to noise ratio (SNR) of the ACAM measurement. From the standard deviations of the fitting residuals, the SNRs of ACAM nadir measurements are estimated to vary from $\sim 300$ at $310 \mathrm{~nm}$ to $\sim 1000$ in the blue spectral region; the zenith data are noisier due to reduced levels of illumination and lower system throughput and also show many more pixels with abrupt anomalous values; therefore, a new method is developed to derive a solar irradiance reference at the top of the atmosphere (TOA) from average nadir measurements, at instrument spectral resolution and including instrument calibration characteristics. Using this reference can significantly reduce fitting residuals and improve the retrievals. This approach derives an absolute reference for direct fitting algorithms involving radiative transfer calculations and thus can be applied to both aircraft and ground-based measurements. The comparison of ACAM radiance with simulations using coincident ozonesonde and OMI data shows large wavelength-dependent biases in ACAM data, varying from -19\% at $310 \mathrm{~nm}$ to $5 \%$ at $360 \mathrm{~nm}$. Correcting ACAM radiance in direct-fitting based ozone profile algorithm significantly improves the consistency with OMI total ozone.
\end{abstract}

\section{Introduction}

The Airborne Compact Atmospheric Mapper (ACAM) is an Ultraviolet (UV)/visible/near-infrared spectrometer covering the spectral range 304-910 $\mathrm{nm}$ [1]. It has been flown on board the NASA UC-12 aircraft in both nadir-viewing mode and much less frequently in zenith-sky mode during the DISCOVER-AQ campaigns as the primary airborne instrument to provide remote sensing column abundances of $\mathrm{O}_{3}$, $\mathrm{NO}_{2}$, and $\mathrm{CH}_{2} \mathrm{O}$ and explore column observations including profiles of partial $\mathrm{O}_{3}$ columns [2].

To retrieve $\mathrm{O}_{3}$ profiles or trace gas vertical column densities (VCDs) from ACAM data by directly fitting the radiance and using the optimal estimation inversion technique, it is critical to perform accurate radiometric calibration and characterize the signal to noise ratio (SNR) of the measurements as measurement constraint $[3,4]$. Liu et al. [3] performed empirical radiometric calibration of OMI data by comparing measured radiance with simulated radiance using zonal mean Microwave Limb Sounder (MLS) $\mathrm{O}_{3}$ profiles in the stratosphere and climatological $\mathrm{O}_{3}$ profiles in the troposphere. A similar method can be applied to ACAM measurements but using simultaneously observed $\mathrm{O}_{3}$ sonde profiles during the DISCOVER-AQ campaigns. The SNR of ACAM measurements can be determined through examining the random part of the fitting residuals.

Because it is impossible to measure extraterrestrial solar irradiance spectrum with the same instrument for groundbased or aircraft UV/visible spectroscopic measurements, various methods have been used to obtain reference spectra for retrieving trace gas abundance from these measurements. The classical Langley extrapolation method derives the extraterrestrial solar irradiance by extrapolating measured irradiance to zero air mass to remove the effects of 
the atmosphere [5-7]. It has been commonly used for Brewer and Dobson measurements to measure $\mathrm{O}_{3}$ and aerosol optical depth, but it has to be done at a very clean atmospheric site (e.g., Mauna Loa, Hawaii) under very special conditions (e.g., cloudless, with little atmospheric variation during the measurement period of a few hours in the morning or afternoon). Atmospheric variability and instrument instability can cause errors in top of the atmosphere (TOA) solar irradiance derived by this way. A more widely used method, especially for retrieving trace gases from UV/visible spectra, is to use zenith-sky or clean background measurements as references [8-16]. Retrievals performed using such reference spectra result in differential quantities between measured and reference spectra. Statistical approaches like minimumamount Langley extrapolation (MLE) and the bootstrapestimation methods or other correlative measurements are often used to derive the offset in the reference spectra $[9,17]$. In addition, it is more complicated to use such reference spectra in direct fitting of radiance with radiative transfer calculations to derive absolute quantities from both nadir and zenith-sky measurements. Tzortziou et al. [18] convolved calibrated high-resolution solar irradiance reference [19] with instrument slit functions to derive the extraterrestrial solar irradiance spectrum from ground-based Pandora measurements for retrieving absolute total $\mathrm{O}_{3}$. However, radiometric/wavelength calibration differences between high-resolution reference and measurements often cause large errors to minor trace gas determinations. In this paper, a novel technique is developed to derive TOA solar irradiance reference spectrum from aircraft nadir/zenith measurements.

The main purpose of this paper is to perform ACAM absolute radiometric calibration, characterize instrument measurement SNR, and derive proper TOA reference spectrum for improving trace gas retrievals from ACAM measurements during the 2011 Baltimore-Washington D.C. DISCOVER-AQ campaign. It is organized as follows. The ACAM instrument and data analysis are described in Section 2. Section 3 focuses on the wavelength and slit function calibration and characterization of ACAM SNR and identification of problematic spectral pixels. Section 4 presents a new method of deriving TOA solar irradiance reference spectrum. Section 5 concludes this study.

\section{ACAM Instrument and Data Analysis}

The Airborne Compact Atmospheric Mapper (ACAM) flown on board the NASA UC-12 aircraft was designed and built at the NASA Goddard Space Flight Center (GSFC). The science objectives of ACAM are to provide remote sensing observations of tropospheric and boundary layer pollutants to help understand some of the most important pollutants that directly affect the health of the population. The ACAM instrument includes two spectrographs, the air quality (AQ) spectrometer and the ocean color (OC) spectrograph. The first one, the UV/Visible AQ spectrometer, covers the $304 \mathrm{~nm}$ to $520 \mathrm{~nm}$ spectral region at a moderate resolution of $0.8 \mathrm{~nm}$. It is optimized for the measurement of tropospheric pollutants and water vapor. The second one, the OC spectrograph, covers the spectral region ranging from $460 \mathrm{~nm}$ to $900 \mathrm{~nm}$ with a resolution of $1.5 \mathrm{~nm}$ optimized for ocean color, water vapor, and aerosols. They operate in two viewing modes, nadir and zenith view, with a spatial resolution of $\sim 1.5 \times$ $0.75 \mathrm{~km}^{2}$ for nadir view. A detailed description of ACAM instrument can be found in [1].

The SAO basic optical absorption spectroscopy (BOAS) trace gas fitting algorithm is adapted to perform wavelength and slit function calibration and spectral fitting of trace gases [20] and has been described in detail in Liu et al. [21]. In this study, we use the derived broadened Gaussian slit function parameters from ACAM data [21] for preconvolution of trace gas cross sections. The fitting algorithm is quite sensitive to the input parameter settings such as retrieval fitting window, the order of polynomials which is used to remove the slow variation of observed spectrum, and the involved absorption of the other trace gases. In this study, through intensive investigations, $\mathrm{O}_{3}, \mathrm{NO}_{2}$, and $\mathrm{HCHO}$ are optimized mainly by using new fitting window $318-335 \mathrm{~nm}, 430-485 \mathrm{~nm}$, and $324-$ $457 \mathrm{~nm}$, respectively.

\section{Instrument SNR Characterizations and Radiometric Calibration}

The fitting residuals contain a systematic component as well as a random component. The standard deviation (i.e., random component) of mean fitting residuals can generally be used to characterize the SNR of the ACAM measurements. Figure 1 shows standard deviations of fitting residuals for three fitting windows derived from one day of ACAM nadir viewing and zenith-sky data on July 21, 2011. In general, they reflect the SNR of ACAM spectral pixels except for some anomalous pixels, especially in the zenith-sky measurements. The SNR of nadir measurements increases from $\sim 300$ around $310 \mathrm{~nm}$ to $\sim 700$ at $340 \mathrm{~nm}$ and 1000 in the blue spectral region. Note that ACAM measurements have 8 samples per FWHM, which effectively enhances the SNR by a factor of 1.63 compared to measurements with 3 samples per FWHM (e.g., OMI). The zenith data are noisier due to reduced levels of illumination and lower system throughput through the zenith fiber port. The anomalous pixels in zenith data are probably linked to instrument radiometric calibration problems and suggest that the current quality of zenith data is inadequate as a reference for retrieving trace gases from nadir measurements. We have identified these pixels with spikes in a previous version of the nadir data and reported them to the ACAM calibration team. They informed us that most of these pixels are affected by inadequate dark current correction. As shown in Figure 1; most of these spikes have been removed in the latest version of ACAM nadir data. They might be removed from zenith measurements in the future.

In order to investigate the quality of ACAM radiometric calibration and perform necessary corrections to ACAM radiance for direct fitting of radiance with radiative calculations, we compare ACAM radiance with simulated radiance using the vector linearized discrete ordinate radiative transfer model (VLIDORT) [22], similar to the comparison described in Liu et al. [3]. To improve the accuracy of the simulation, 


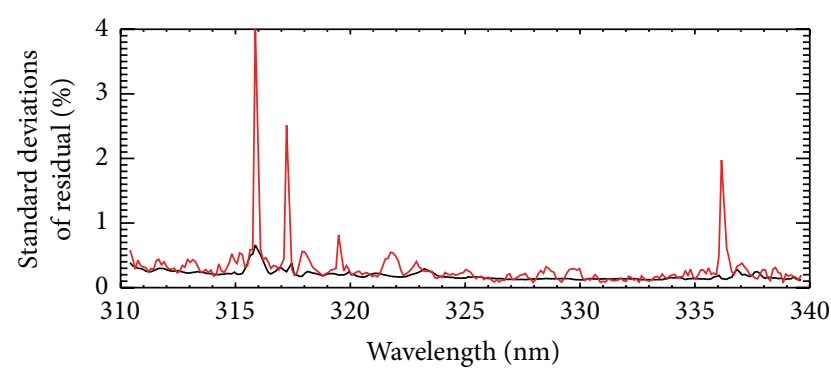

(a)

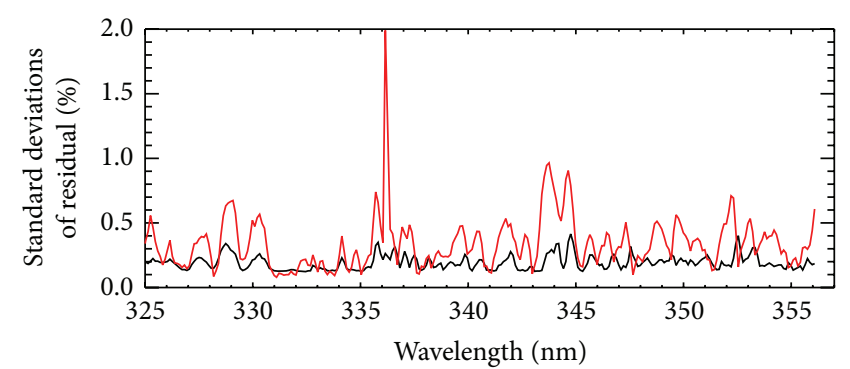

(b)

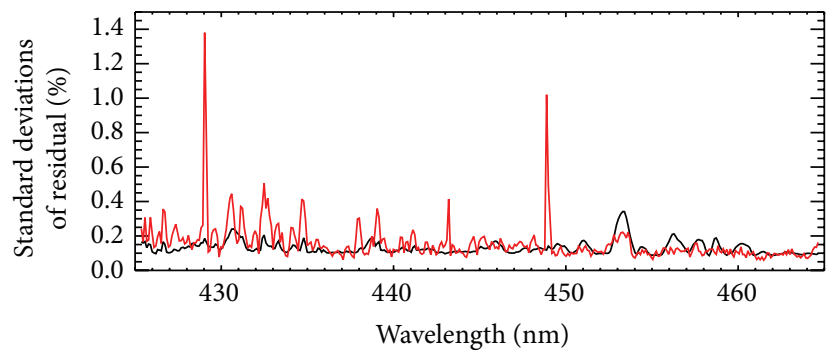

(c)

FIGURE 1: Standard deviations of fitting residuals from both zenith (red) and nadir (black) measurements of the ACAM AQ channel on July 21, 2011, for three selected wavelength ranges: (a) $\mathrm{O}_{3}$ fitting window, (b) $\mathrm{CH}_{2} \mathrm{O}$ fitting window, and (c) $\mathrm{NO}_{2}$ fitting window.

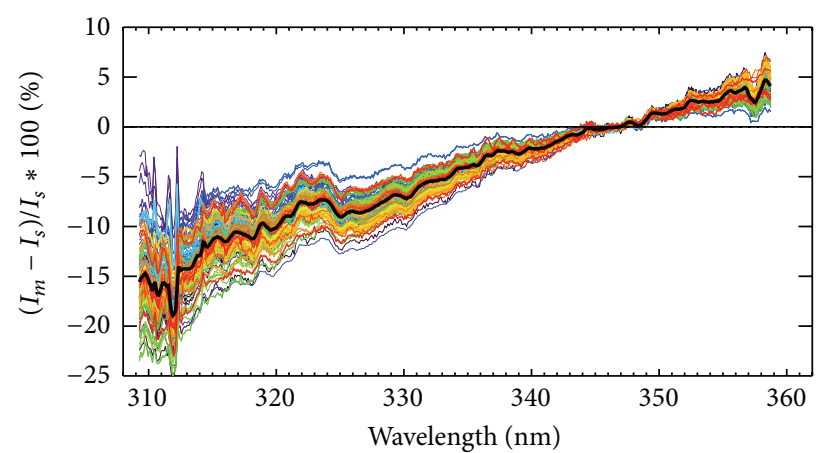

(a)

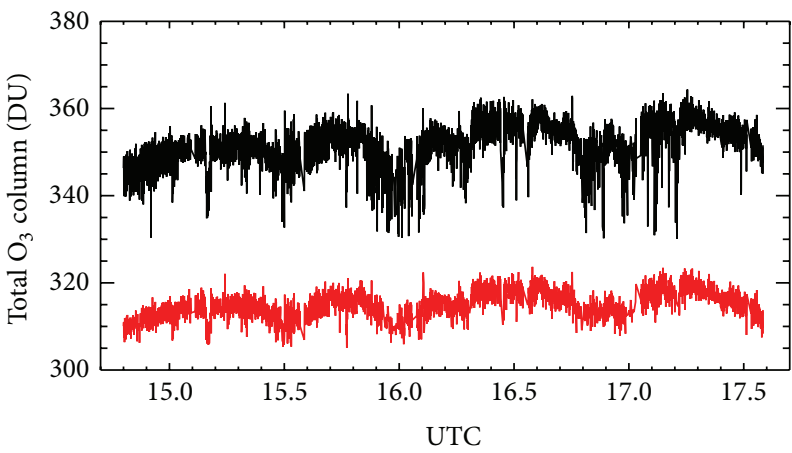

(b)

Figure 2: (a) Difference between ACAM $\left(I_{m}\right)$ and simulated $\left(I_{s}\right)$ radiance versus wavelength for 158 ozonesonde/ACAM collocations (within 2 hours and $1 \mathrm{~km}$ ) in different colors, for the 2011 DISCOVER-AQ flight campaign. The average difference (black) is used as the empirical radiometric correction. (b) Retrieved total ozone column with (black) and without (red) using the derived empirical correction from ACAM radiance in the spectral region 318-335 nm from July 21, 2011, using the optimal estimation based ozone profile algorithm.

we use ozonesonde profiles measured at Beltsville $\left(39.1^{\circ} \mathrm{N}\right.$, $\left.76.9^{\circ} \mathrm{W}\right)$ and Edgewood $\left(39.4^{\circ} \mathrm{N}, 76.3^{\circ} \mathrm{W}\right)$ during the 2011 DISCOVER-AQ flight campaign collocated with ACAM observations within 2 hours and $0.01^{\circ}$ longitude and latitude below $100 \mathrm{hPa}$ and scaled climatologically stratospheric ozone profiles from McPeters et al. [23] to match the daily overpass $\mathrm{OMI} \mathrm{O}_{3}$ total ozone column (within 6 hours and $0.07^{\circ}$ latitude and $1^{\circ}$ longitude, $6 \mathrm{DU}$ added to account for known systematic offset in the OMTO3 caused by the use of the Bass and Paur cross sections). A total of 158 collocations with 48 ozonesonde profiles are used in the simulations.

Figure 2(a) shows individual percentage differences between ACAM and simulated radiance in the spectral range $309-360 \mathrm{~nm}$ for all the collocations (in colors) and the average difference (black). The average difference varies from $\sim-19 \%$ to $\sim 5 \%$ showing significant wavelength dependence. The difference is zero at $347.2 \mathrm{~nm}$ as we derive cloud information from this wavelength region by matching simulated and ACAM radiance. Thus, these are relative wavelength-dependent differences, which actually matter to the ozone profile algorithm [3]. There is significant variability in the derived differences $(\sim 10 \%$ at $310 \mathrm{~nm}$ and $\sim 5 \%$ at $360 \mathrm{~nm}$ ) due to mismatch in time and location and uncertainties/errors in used ozone profiles. The presence of consistent overall features for these collocations indicates the existence of wavelength-dependent radiometric calibration errors in current ACAM data. The ACAM calibration team is currently revisiting ACAM's absolute radiometric calibration for 
improvement, particularly in removing the stray light component which becomes increasingly important at wavelengths below $350 \mathrm{~nm}$. To show the importance of applying this correction to the optimal estimation based ozone profile algorithm [3] modified for ACAM data, we apply an empirical correction to both ACAM radiance using the average difference and retrieve ozone profile from ACAM radiance in the spectral region $318-335 \mathrm{~nm}$ on July 21, 2011. Figure 2(b) compares the retrieved total ozone with and without applying this correction. After applying the correction, the total ozone is significantly reduced, by $\sim 35 \mathrm{DU}$, more consistent with the overpass OMI total ozone column of $309 \pm 0.6 \mathrm{DU}$, and appears to be less noisy.

\section{Derived TOA Solar Irradiance Reference}

A new method is developed to derive the TOA solar irradiance reference spectrum over a spectral window from ACAM nadir measurements. First, we choose several hundred nadir measurements with similar radiance and have relatively small SCDs (through initial spectral fitting) of the target trace gas (i.e., for $\mathrm{NO}_{2}$ and $\mathrm{CH}_{2} \mathrm{O}$ ) and derive an average nadir radiance spectrum $\overline{I_{n}}(\lambda)$. The averaging of nadir measurements at similar radiance significantly reduces random noise in the measurements. Second, we use the high-resolution solar reference spectrum $I_{h 0, \lambda}$ convolved with derived slit functions to fit $\overline{I_{n}}(\lambda)$ over a fitting window larger than the target trace gas fitting window by $\sim 2 \mathrm{~nm}$ on both sides while simulating the radiance spectrum. The fitted trace gas SCDs come from two parts: (a) the actual trace gas in the atmosphere contained in $\overline{I_{n}}(\lambda)$ and (b) the artifacts from the use of $I_{h 0, \lambda}$, which introduces structures similar to some of the target trace gas. Typically, the former is much larger for $\mathrm{O}_{3}$, but the latter is much larger for minor trace gases. Third, by replacing $I_{s}(\lambda)$ with $\overline{I_{n}}(\lambda)$ and applying all the fitted parameters in the reverse process, we can derive the TOA solar irradiance according to

$$
I_{\mathrm{TOA}, n}(\lambda)=\frac{\left\{\left[\left(\overline{I_{n}}(\lambda)-P_{b}(\lambda)\right) / P_{s}(\lambda)-\sum_{i} a_{2, i} X_{2, i}(\lambda)\right] \exp \left(\sum_{i} n_{i} \sigma_{i}(\lambda)\right)-\sum_{i} a_{1, i} X_{1, i}(\lambda)\right\}}{A}
$$

$A$ is the scaling parameter. $X_{1, i}(\lambda), \sigma_{i}(\lambda)$, and $X_{2, i}(\lambda)$ are the basis functions in initial add-on, Beer's law, and second add-on modes, respectively, and $a_{1, i}, n_{i}$, and $a_{2, i}$ are the corresponding coefficients. The basis functions can include trace gas cross sections, Ring effect, undersampling spectra, and common residual spectra. Each basis function is typically included in only one of the modes (e.g., cross sections as $\sigma_{i}$, Ring effect (Chance and Spurr, 1997) as $X_{1, i}$, and common mode as $\left.X_{2, i}\right) . P_{s}(\lambda)$ and $P_{b}(\lambda)$ are the scaling and baseline polynomials, respectively. An option to the above process is whether to apply $n_{i}$ of the target trace gas. Applying $n_{i}$ cancels the part in $\overline{I_{n}}(\lambda)$, leaving the artifact part in the $I_{\mathrm{TOA}, n}(\lambda)$. On the other hand, not applying $n_{i}$ cancels the artifact part, leaving the part from $\overline{I_{n}}(\lambda)$ in the $I_{\mathrm{TOA}, n}(\lambda) \cdot I_{\mathrm{TOA}, n}(\lambda)$ contains a systematic offset from the target gas in either case. To reduce the systematic offset, we apply $n_{i}$ for $\mathrm{O}_{3}$ and do not apply $n_{i}$ for other minor trace gases.

The derived $I_{\mathrm{TOA}, n}(\lambda)$ is a solar irradiance reference at instrument spectral resolution that includes instrument calibration characteristics. When it is used as a reference in the trace gas retrievals, it cancels most of the systematic instrument calibration features, leading to improved relative root mean square (RMS) values of the fitting residuals as shown in the next paragraph. It can be derived from either nadir or zenith measurements but, due to much more frequent nadir measurements and their higher qualities (as shown in Figure 1), we derive TOA solar reference using the nadir measurements. This method can also be applied to ground-based measurements or satellite measurements if high quality solar irradiance measurements are not available. Although it contains some systematic offset, it can be used as an absolute reference spectrum for direct fitting algorithms involving radiative calculations (e.g., ozone profile retrieval algorithm) from both nadir and zenith measurements.

To show the retrieval improvement using our derived $I_{\mathrm{TOA}, n}(\lambda)$, we compare retrievals of $\mathrm{O}_{3}, \mathrm{CH}_{2} \mathrm{O}$, and $\mathrm{NO}_{2} \mathrm{SCDs}$ using three references in Figure 3. The other two references for comparison are the average zenith-sky reference and the TOA solar irradiance reference $I_{\mathrm{TOA}}(\lambda)$ by directly convolving the high-resolution solar irradiance spectrum with ACAM slit functions using (1). $I_{\mathrm{TOA}}(\lambda)$ is very similar to our derived $I_{\mathrm{TOA}, n}(\lambda)$ except that it does not contain ACAM calibration features. Using $I_{\mathrm{TOA}, n}(\lambda)$ significantly reduces fitting RMS values and fitting uncertainties especially for $\mathrm{CH}_{2} \mathrm{O}$ and $\mathrm{NO}_{2}$ by more than a factor of 3 and 4 . The average zenith reference gives better precision for $\mathrm{CH}_{2} \mathrm{O}$ fitting, comparable fitting precision and better RMS uncertainties for $\mathrm{NO}_{2}$ fitting, and worse precision for $\mathrm{O}_{3}$, compared to the $I_{\mathrm{TOA}}(\lambda)$. Although the zenith reference is also measured by the ACAM instrument, the large fitting RMS is likely due to the optical path difference of zenith port from the nadir port, by using additional optical fibers, systematic calibration differences between zenith and nadir data, and poorer SNR in the zenith data. Both TOA solar irradiance references are absolute references, giving actual SCDs in the atmosphere, while the average zenith reference is a relative reference, giving very small or even negative $\mathrm{O}_{3}$ SCDs especially when the solar zenith angle is small. However, for $\mathrm{CH}_{2} \mathrm{O}$ and $\mathrm{NO}_{2}$ fitting, using $I_{\mathrm{TOA}}(\lambda)$ leads to large systematic offsets, $\sim 2 \times 10^{17}$ and $\sim 10^{16}$ molecules $\mathrm{cm}^{-2}$ for $\mathrm{CH}_{2} \mathrm{O}$ and $\mathrm{NO}_{2}$, respectively, mainly due to artifacts from the convolved solar irradiance. Compared to $I_{\mathrm{TOA}, n}(\lambda)$, the zenith reference gives similar $\mathrm{NO}_{2}$ SCDs but larger $\mathrm{CH}_{2} \mathrm{O}$ SCDs by $\sim 4 \times$ $10^{16}$ molecules $\mathrm{cm}^{-2}$. 

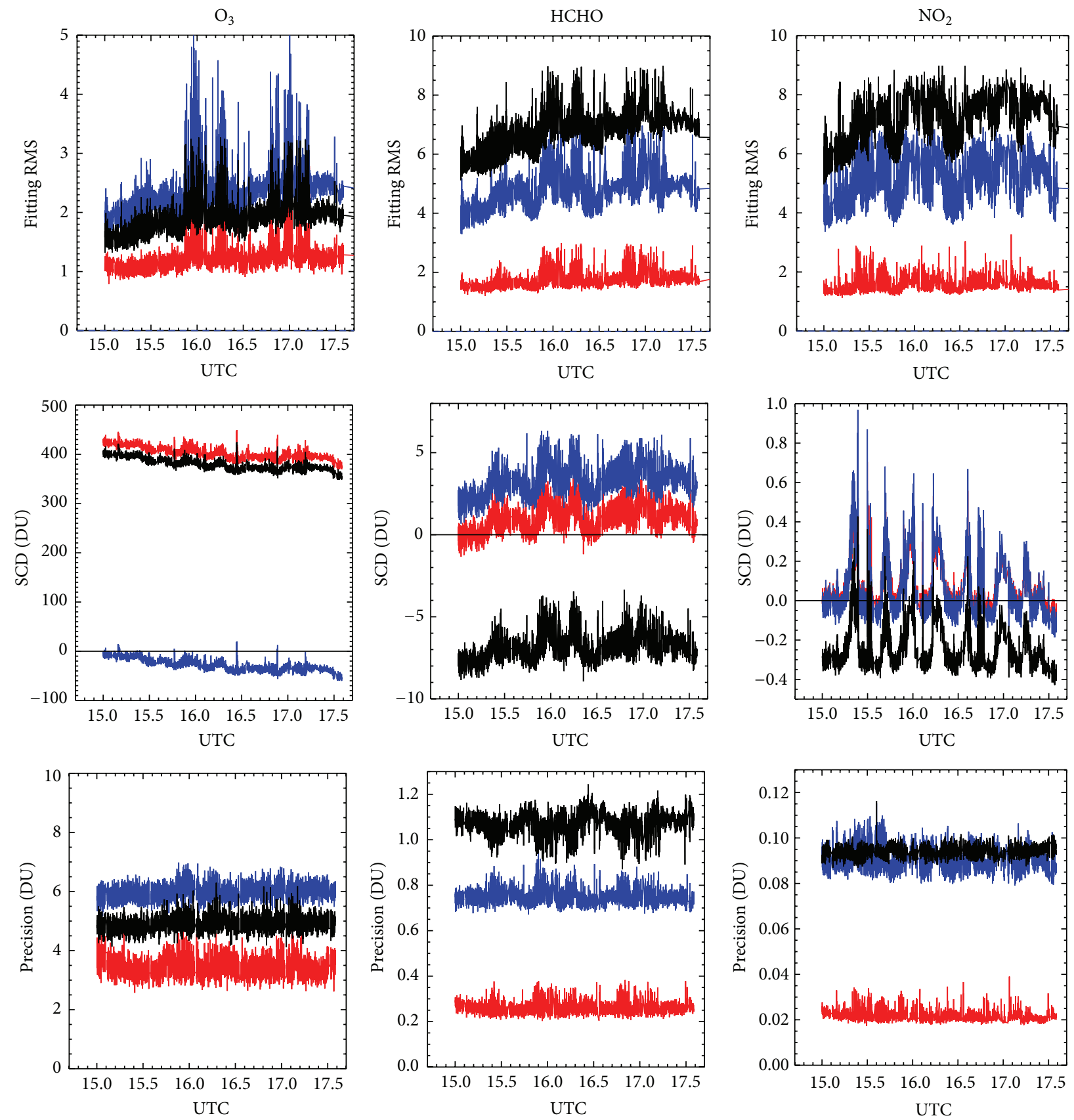

FIGURE 3: Comparison of $\mathrm{O}_{3}$ (left), $\mathrm{CH}_{2} \mathrm{O}$ (middle column), and $\mathrm{NO}_{2}$ (right) fitting in (top) relative RMS, (middle row) SCDs, and (bottom) precision of SCDs for ACAM measurements from July 21, 2011, using three different reference spectra: average zenith reference (blue), highresolution solar irradiance convolved with instrument slit functions (black), and derived TOA solar irradiance from average nadir radiance spectrum (red).

\section{Summaries}

In this study we estimate the SNRs and identify anomalous spectral pixels in the data from standard deviations of the fitting residuals. The SNRs for ACAM nadir measurements increase from $\sim 300$ around $310 \mathrm{~nm}$ to $\sim 700$ at $340 \mathrm{~nm}$ and 1000 in the blue spectral region. The zenith data are noisier and show many more anomalous pixels, indicating dark current calibration problems. This also suggests that the current quality of zenith spectra is insufficient as reference spectra for trace gas retrievals. Using collocated ozonesonde measurements in the troposphere and climatological $\mathrm{O}_{3}$ in the stratosphere scaled to match overpass OMI total ozone column, we simulated radiance and compared them with ACAM radiance in the UV $(\sim 309-360 \mathrm{~nm})$. The average differences show strong wavelength dependence, varying from $\sim-19 \%$ at $310 \mathrm{~nm}$ to $5 \%$ at $360 \mathrm{~nm}$, indicating the presence of large wavelength-dependent radiometric calibrations errors in the 
current ACAM data. Using the average difference as the correction to ACAM radiance, we evaluated the impact of this correction on the retrieved total ozone using the optimal estimation based ozone profile algorithm. The correction reduces the total ozone by $\sim 35 \mathrm{DU}$, making it more consistent with the coincident OMI total ozone.

We developed a new method to derive the TOA solar irradiance reference at instrument spectral resolution, including instrument calibration characteristics, from aircraft nadir measurements through reversing the calibration process. We compared the performance of retrieving $\mathrm{O}_{3}, \mathrm{CH}_{2} \mathrm{O}$, and $\mathrm{NO}_{2}$ SCDs using this derived TOA reference with those using an average zenith reference and a TOA reference by directly convolving high-resolution solar irradiance with derived instrument slit functions. Using our derived TOA reference significantly reduces fitting RMS/uncertainty (by a factor of 3 and 4 for $\mathrm{CH}_{2} \mathrm{O}$ and $\mathrm{NO}_{2}$ ). It gives absolute $\mathrm{O}_{3}$ SCDs compared to the zenith reference and significantly reduces the artificial offsets in $\mathrm{CH}_{2} \mathrm{O}$ and $\mathrm{NO}_{2}$ SCDs compared to the directly convolved TOA reference. This method can be applied to both aircraft and ground-based measurements to derive retrieval reference spectra, which can serve as absolute reference for direct fitting algorithms involving radiative calculations, although it still causes systematic offsets in the derived quantities as do most of the conventional reference spectra for aircraft/ground-based measurements.

\section{Disclosure}

The current address for C. Liu is University of Science and Technology of China, Hefei, Anhui, China.

\section{Conflict of Interests}

The authors declare that there is no conflict of interests regarding the publication of this paper.

\section{Acknowledgments}

Funding for this work at SAO is provided by NASA Grants NNX11AH77G and NNX12AJ66G as part of the NASA Earth Venture-1 DISCOVER-AQ project and by the Smithsonian Institution. The authors thank Anne Thompson (NASA/ GSFC) and Everette Joseph (Howard University) who provided the ozonesonde data from the Edgewood and Beltsville sites, respectively. They acknowledge James Crawford for his strong support on this work.

\section{References}

[1] M. G. Kowalewski and S. J. Janz, "Remote sensing capabilities of the airborne compact atmospheric mapper," in Earth Observing Systems XIV, vol. 7452 of Proceedings of SPIE, San Diego, Calif, USA, August 2009.

[2] X. Liu, K. Chance, C. E. Sioris et al., "Ozone profile and tropospheric ozone retrievals from global ozone monitoring experiment: algorithm description and validation," Journal of Geophysical Research, vol. 110, Article ID D20307, 2005.
[3] X. Liu, P. K. Bhartia, K. Chance, R. J. D. Spurr, and T. P. Kurosu, "Ozone profile retrievals from the ozone monitoring instrument," Atmospheric Chemistry and Physics, vol. 10, no. 5, pp. 2521-2537, 2010.

[4] C. R. Nowlan, X. Liu, K. Chance et al., "Retrievals of sulfur dioxide from the global ozone monitoring experiment 2 (GOME2) using an optimal estimation approach: algorithm and initial validation," Journal of Geophysical Research: Atmospheres, vol. 116, no. 18, 2011.

[5] J. Gröbner and J. B. Kerr, "Ground-based determination of the spectral ultraviolet extraterrestrial solar irradiance: providing a link between space-based and ground-based solar UV measurements," Journal of Geophysical Research: Atmospheres, vol. 106, no. 7, Article ID 2000JD900756, pp. 7211-7217, 2001.

[6] A. F. Bais, "Absolute spectral measurements of direct solar ultraviolet irradiance with a Brewer spectrophotometer," Applied Optics, vol. 36, no. 21, pp. 5199-5204, 1997.

[7] A. Cheymol, H. De Backer, W. Josefsson, and R. Stübi, "Comparison and validation of the aerosol optical depth obtained with the Langley plot method in the UV-B from Brewer Ozone Spectrophotometer measurements," Journal of Geophysical Research: Atmospheres, vol. 111, no. 16, Article ID D16202, 2006.

[8] K.-P. Heue, A. Richter, M. Bruns et al., "Validation of SCIAMACHY tropospheric $\mathrm{NO}_{2}$-columns with AMAXDOAS measurements," Atmospheric Chemistry and Physics, vol. 5, no. 4, pp. 1039-1051, 2005.

[9] J. Herman, A. Cede, E. Spinei, G. Mount, M. Tzortziou, and N. Abuhassan, " $\mathrm{NO}_{2}$ column amounts from ground-based Pandora and MFDOAS spectrometers using the direct-sun DOAS technique: intercomparisons and application to OMI validation," Journal of Geophysical Research: Atmospheres, vol. 114, no. 13, Article ID D13307, 2009.

[10] H. K. Roscoe, M. Van Roozendael, C. Fayt, and et al, "Intercomparison of slant column measurements of $\mathrm{NO}_{2}$ and $\mathrm{O}_{4}$ by MAX-DOAS and zenith-sky UV and visible spectrometers," Atmospheric Measurement Techniques, vol. 3, no. 6, pp. 1629$1646,2010$.

[11] R. Sinreich, S. Coburn, B. Dix, and R. Volkamer, "Ship-based detection of glyoxal over the remote tropical Pacific Ocean," Atmospheric Chemistry and Physics, vol. 10, no. 23, pp. 11359$11371,2010$.

[12] H. Irie, H. Takashima, Y. Kanaya et al., "Eight-component retrievals from ground-based MAX-DOAS observations," Atmospheric Measurement Techniques, vol. 4, no. 6, pp. 10271044, 2011.

[13] T. Vlemmix, A. J. M. Piters, A. J. C. Berkhout, L. F. L. Gast, P. Wang, and P. F. Levelt, "Ability of the MAX-DOAS method to derive profile information for $\mathrm{NO}_{2}$ : can the boundary layer and free troposphere be separated?" Atmospheric Measurement Techniques, vol. 4, no. 12, pp. 2659-2684, 2011.

[14] C. Popp, D. Brunner, A. Damm, M. Van Roozendael, C. Fayt, and $\mathrm{B}$. Buchmann, "High-resolution $\mathrm{NO}_{2}$ remote sensing from the Airborne Prism EXperiment (APEX) imaging spectrometer," Atmospheric Measurement Techniques, vol. 5, no. 9, pp. 22112225, 2012.

[15] A. Merlaud, M. van Roozendael, J. van Gent et al., "DOAS measurements of $\mathrm{NO}_{2}$ from an ultralight aircraft during the Earth Challenge expedition," Atmospheric Measurement Techniques, vol. 5, no. 8, pp. 2057-2068, 2012.

[16] G. Pinardi, M. Van Roozendae, N. Abuhassan et al., "MAXDOAS formaldehyde slant column measurements during 
CINDI: intercomparison and analysis improvement," Atmospheric Measurement Techniques, vol. 6, pp. 167-185, 2013.

[17] A. Cede, J. Herman, A. Richter, N. Krotkov, and J. Burrows, "Measurements of nitrogen dioxide total column amounts using a Brewer double spectrophotometer in direct Sun mode," Journal of Geophysical Research, vol. 111, p. 5304, 2006.

[18] M. Tzortziou, J. R. Herman, A. Cede, and N. Abuhassan, "High precision, absolute total column ozone measurements from the Pandora spectrometer system: comparisons with data from a Brewer double monochromator and Aura OMI," Journal of Geophysical Research: Atmospheres, vol. 117, no. 16, Article ID 16303, 2012.

[19] K. Chance and R. L. Kurucz, "An improved high-resolution solar reference spectrum for earth's atmosphere measurements in the ultraviolet, visible, and near infrared," Journal of Quantitative Spectroscopy and Radiative Transfer, vol. 111, no. 9, pp. 1289-1295, 2010.

[20] K. Chance, "Analysis of BrO measurements from the Global Ozone Monitoring Experiment," Geophysical Research Letters, vol. 25, no. 17, pp. 3335-3338, 1998.

[21] C. Liu, X. M. G. Liu, S. J. Kowalewski et al., "Characterization and verification of ACAM slit functions for trace gas retrievals during the 2011 DISCOVER-AQ flight campaign," Atmospheric Measurement Techniques, vol. 8, pp. 751-759, 2015.

[22] R. J. D. Spurr, "VLIDORT: a linearized pseudo-spherical vector discrete ordinate radiative transfer code for forward model and retrieval studies in multilayer multiple scattering media," Journal of Quantitative Spectroscopy and Radiative Transfer, vol. 102, no. 2, pp. 316-342, 2006.

[23] R. D. McPeters, G. J. Labow, and J. A. Logan, "Ozone climatological profiles for satellite retrieval algorithms," Journal of Geophysical Research, vol. 112, no. 5, Article ID D05308, 2007. 

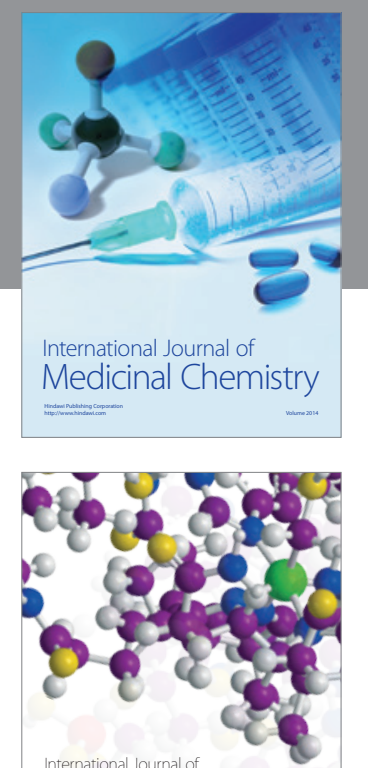

\section{Carbohydrate} Chemistry

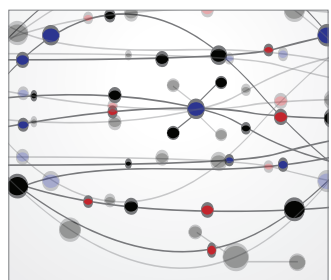

The Scientific World Journal
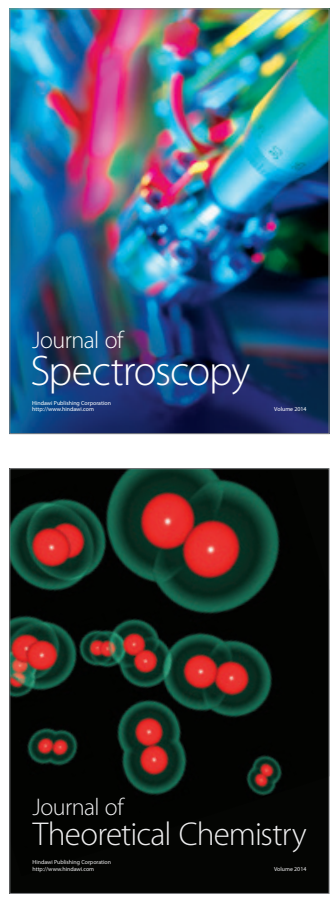
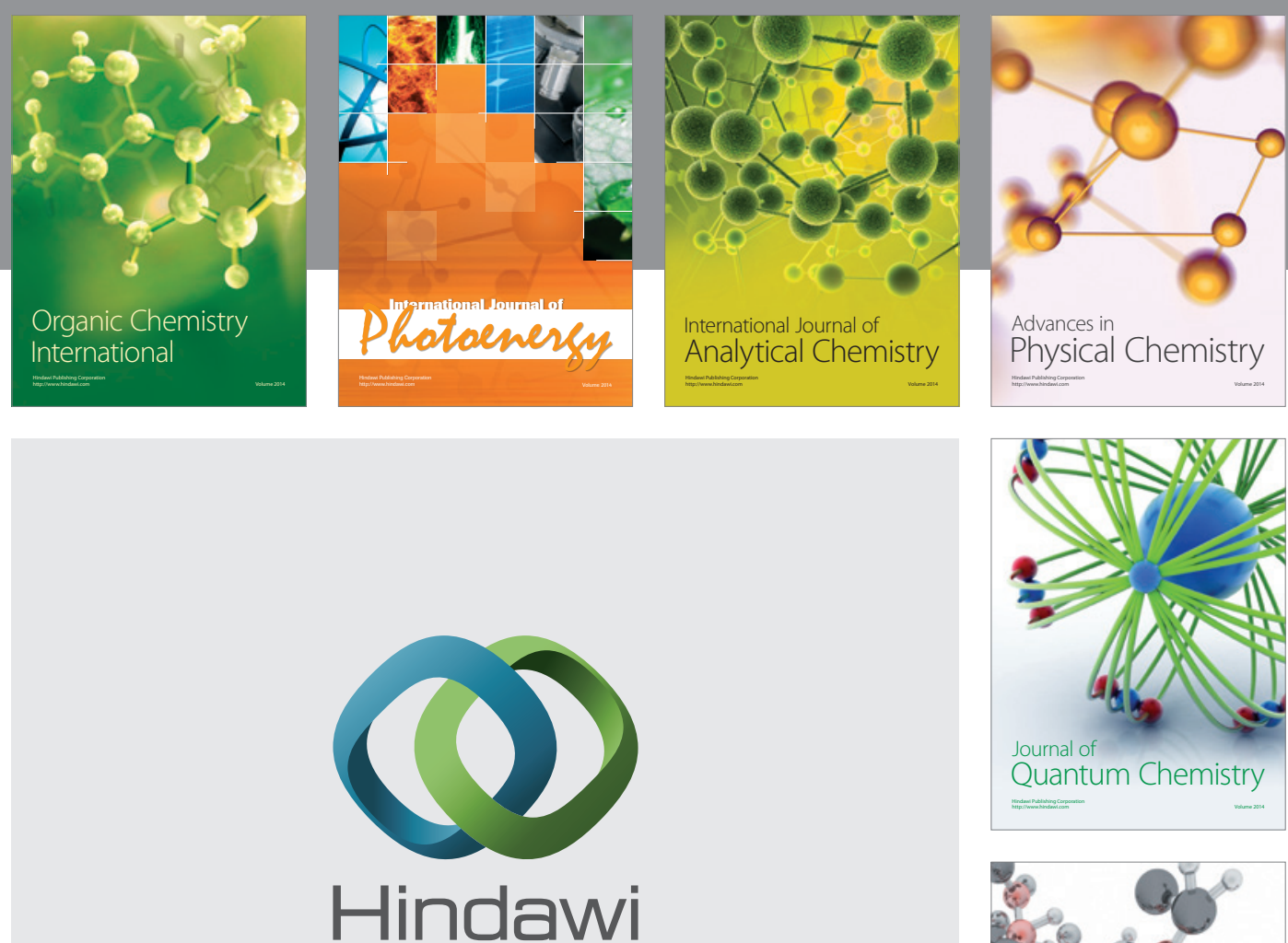

Submit your manuscripts at

http://www.hindawi.com

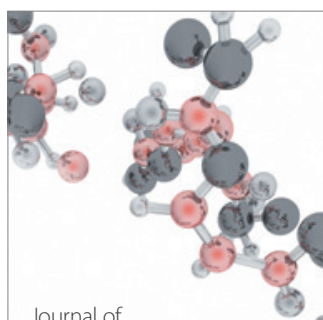

Analytical Methods

in Chemistry

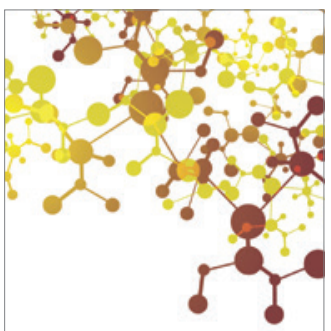

Journal of

Applied Chemistry

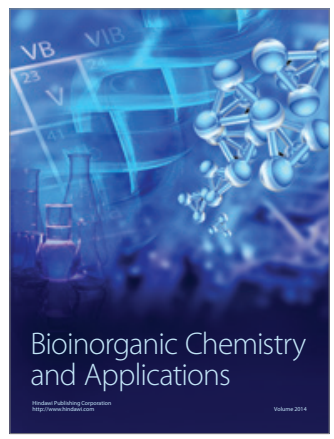

Inorganic Chemistry
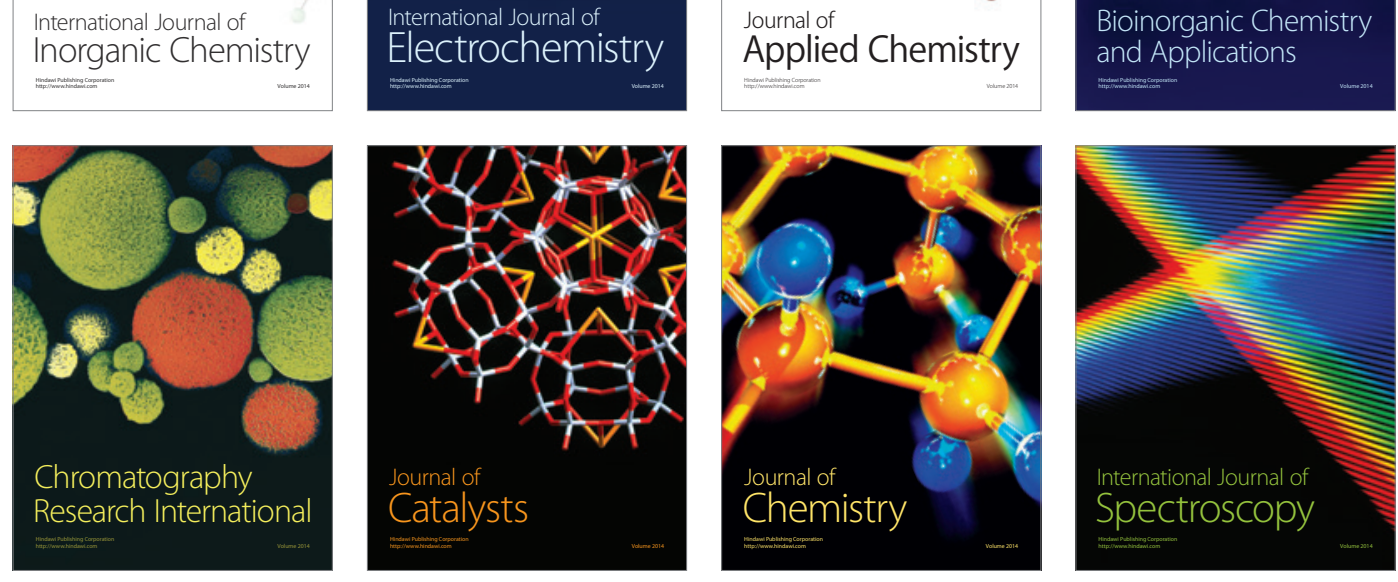